\title{
Examining side effect variation of antipsychotic treatment in schizophrenia spectrum disorders
}

\author{
Maria S. Neumeier ${ }^{1}$, Stephanie Homan, Ph.D. ${ }^{1}$, Stefan Vetter, M.D. ${ }^{1}$, Erich Seifritz, M.D. ${ }^{1}$, John M. Kane, \\ M.D. ${ }^{2,3,4}$, Maximilian Huhn, M.D. ${ }^{5}$, Stefan Leucht, M.D. ${ }^{5}$, \& Philipp Homan, M.D., Ph.D. ${ }^{1,2,3,4^{*}}$ \\ ${ }^{1}$ University Hospital of Psychiatry Zurich, Zurich, Switzerland. \\ ${ }^{2}$ Center for Psychiatric Neuroscience, Feinstein Institute for Medical Research, Manhasset, NY, USA. \\ ${ }^{3}$ Division of Psychiatry Research, Zucker Hillside Hospital, Northwell Health, New York, NY, USA. \\ ${ }^{4}$ Department of Psychiatry, Zucker School of Medicine at Northwell/Hofstra, Hempstead, NY, USA. \\ ${ }^{5}$ Department of Psychiatry and Psychotherapy, Technical University of Munich, School of Medicine, Munich, Germany.
}

\begin{abstract}
Background: Side effects of antipsychotic drugs play a key role in non-adherence and discontinuation of treatment in schizophrenia spectrum disorders (SSD). Precision medicine aims to minimize such side effects by selecting the right treatment for the right patient. However, to determine the extent of precision medicine that is required, we need to (1) show that there is indeed variation in side effects and (2) estimate the amount of variation in those side effects between patients. While clinical observations suggest that such variation may be considerable, a statistical comparison of side effect variation between active and control treatments is required to confirm this. Here, we hypothesized to find larger side effect variation in treatment compared with control in patients treated with first and second generation antipsychotics. Methods: We included double-blind, placebo-controlled, randomized controlled trials (RCTs) of adults with a diagnosis of SSD and prescription for licensed antipsychotic drugs. Standard deviations of the pre-post treatment differences of weight gain, prolactin levels, and corrected QT (QTc) times were extracted. Data quality and validity were ensured by following the PRISMA guidelines. The outcome measure was the overall variability ratio of treatment to control across RCTs. Individual variability ratios were weighted by the inverse-variance method and entered into a random-effects model. Results: We included N $=16578$ patients for weight gain, $\mathrm{N}=16633$ patients for prolactin levels, and $\mathrm{N}=10384$ patients for QTc time. Variability ratios (VR) were significantly increased for weight gain (VR =1.08; 95\% CI: 1.02 1.14; $\mathrm{P}=0.004)$ and prolactin levels $(\mathrm{VR}=1.38 ; 95 \% \mathrm{CI}: 1.17-1.62 ; \mathrm{P}<0.001)$ but did not reach significance for QTc time (VR = 1.05; 95\% CI: $0.98-1.12 ; \mathrm{P}=0.135)$. Conclusion: We found increased variability in major side effects in patients with SSD under treatment with second generation antipsychotics, suggesting that subgroups of patients or even individual patients may benefit from improved treatment allocation through stratified or personalized medicine, respectively.
\end{abstract}

\section{Introduction}

Antipsychotics are a fundamental component in the treatment of schizophrenia spectrum disorders (SSD). Yet, a major problem are side effects which play a key role in nonadherence and discontinuation. ${ }^{1-5}$ A common hypothesis among researchers and clinicians alike is that although side effects are pervasive, not all patients are equally susceptible. ${ }^{6}$ However, empirical support for this hypothesis is lacking, as randomized controlled trials (RCTs) or conventional meta analyses by design cannot answer whether such side effect

Correspondence concerning this article should be addressed to Philipp Homan, M.D., Ph.D., University Hospital of Psychiatry Zurich, Lenggstrasse 31, 8032 Zurich, Switzerland. E-mail: philipp.homan@bli.uzh.ch variation does exist. ${ }^{7,8}$

To date, studies have established the efficacy, safety, and side effect profiles of antipsychotic medications by averaging these indices across groups of patients. Such studies can provide us with average side effects, but they cannot tell us anything about individual patients or subgroups. ${ }^{9,10}$ Nevertheless, before searching for potential biomarkers that might predict individual susceptibility, we should first quantify the extent to which such predictors are truly needed.

An approach to answering this question is to shift the focus from the means to the variances of side effects. ${ }^{11}$ By comparing the variances between treatment and control groups of RCTs, ${ }^{12}$ greater variability in treatment would indicate that there is a component of variation, the side effect-by-patient or side effect-by-subgroup interaction, that indicates variability of side effects. ${ }^{11}$ Note that this method ${ }^{13}$ has recently been applied for antipsychotics, ${ }^{7}$ antidepressants, ${ }^{8,14,15}$ and brain stimulation. ${ }^{16}$ It is worth noting that these studies found little 
evidence for treatment effect variation. ${ }^{7,8,14,15}$ Importantly, in the case of pre-post differences used as input for a metaanalysis of variance it is crucial to think carefully about the way the variability ratio is expressed, ${ }^{12,15,17}$ as the use of the coefficient of variation ratio (CVR) that has been proposed as an alternative of the variability ratio $(\mathrm{VR})^{12}$ may lead to unreliable results. ${ }^{13,17}$

A recently published study investigated the individual treatment response in antipsychotics and brought surprising results. ${ }^{7,18}$ By comparing the variability between treatment and control groups, no evidence was found for an increase in variability in the treatment group. What might sound counter-intuitive at first raises the question of how big the need for precision medicine really is. However, that study evaluated the evidence for treatment effect variation. It is possible that although such variation in treatment effects is not as high as sometimes assumed ${ }^{19}$, it does exist in the susceptibility for side effects. In other words, even if there is little variation in response to treatment between patients, there may still be enough variation in side effects to justify a need for precision medicine. If true, then this would support optimization of treatment allocation with respect to side effect profiles. ${ }^{20}$

Side effects that are particularly relevant to antipsychotic treatment include weight gain ${ }^{5}$, hyperprolactinemia, and QTc prolongation. ${ }^{20}$ Weight gain is a frequently observed side effect that can negatively impact one's physical health and thus may also influence treatment adherence. Every additional kilogram of weight gain can contribute to an increased risk of heart failure,${ }^{21}$ cardiovascular diesease, ${ }^{22}$ and diabetes. ${ }^{23}$ In addition, treatment discontinuation is often seen in patients with increase of weight under treatment. ${ }^{24}$ High prolactin levels can lead to symptoms like decreased bone mass, gallactorhea, and fertility problems in men and women. Further possible symptoms include menstrual disturbances in female patients and decreased libido and erectile dysfunction in male patients. ${ }^{25}$ These symptoms are frequent, but often underreported by patients and unnoticed as well as untreated by clinicians. $^{26,27}$ They furthermore might lead to loss in quality of life and might be a reason for treatment discontinuation ${ }^{1,28}$ and subsequent illness relapse, which together with persistent positive symptoms ${ }^{29-32}$ may severly impact recovery and therapeutic alliance. ${ }^{33}$ Prolongation of QTc was observed in 7 of 14 antipsychotics compared by placebo in the intergroup comparision by Huhn and colleagues. ${ }^{6}$ Importantly, torsade de pointes tachycardia and sudden cardiac death are possible severe consequences of QTc prolongation. ${ }^{34}$ Such cardiac events are one of the factors that lead to the loss of life expectancy observed in patients with SSD. ${ }^{35-37}$

In summary, antipsychotic side effects are highly relevant for long-term outcome and adherence in treatment of positive symptoms in SSD. The question remains whether variability in side effects is high enough to warrant efforts of treatment stratification or personalisation. Here, we compared the variances of side effects including weight gain, prolactin level and QTc-time between treatment and control groups to address this question and to evaluate the evidence for the presence of side effect variability. Based on the clinical impression that patients seem to vary in their susceptibility to side effects, we hypothesized that the variability in side effects would be higher in the treatment compared to the control groups across all published trials of antipsychotics in SSD. ${ }^{6}$

\section{Methods}

\section{Search strategy and selection criteria}

We used the data from the recent meta-analysis by Huhn and colleagues. ${ }^{6}$ That study included placebo-controlled published and unpublished trials investigating orally administered atypical (second generation) antipsychotics and typical (first generation) antipsychotics in adults with schizophrenia spectrum disorders; and excluded patients with first episode psychosis, treatment resistance, mainly negative symptoms, comorbidity with other mental or physical illnesses and relapse-prevention studies. Long- and short-acting intramuscular injections were also excluded (as they are often used in relapse prevention or emergency treatment) and studies from mainland China were excluded because of data quality concerns. ${ }^{38}$ Data sources were MEDLINE, Cochrane Central Register of Controlled Trials (CENTRAL), Embase, Biosis, PsycINFO, PubMed, ClinicalTrials.gov, WHO International Clinical Trials Registry Platform and the US Food and Drug Administration until January 8 2019. Data quality and validity were ensured by following the PRISMA guidelines. ${ }^{39}$ For missing data, we also contacted study authors.

For the analysis, we used the standard deviations of pre-post differences in side effects. The primary outcome was the overall variability ratio of side effects in treatment versus control groups. Standard deviations (SD) and number of patients $(\mathrm{N})$ were extracted for weight gain, prolactin level and QTc time. The units used were $\mathrm{kg}$ for weight gain, $\mathrm{ng} / \mathrm{mL}$ for prolactin levels, and ms for QTc time. Some studies provided data for all of the three side effects, whereas the majority of the studies contained less data (see Results).

\section{Statistical analysis}

If patients or subgroups differ in their susceptibility to side effects, we would expect to observe increased variances in the treatment- compared with the control group. To test this, we computed the log variability ratio (log VR) by comparing the relative variability of side effects under treatment versus control:

$$
\log \mathrm{VR}=\log \left(\frac{\mathrm{SD}_{\mathrm{Tx}}}{\mathrm{SD}_{\mathrm{Ct}}}\right)+\frac{1}{2\left(n_{\mathrm{Tx}}-1\right)}-\frac{1}{2\left(n_{\mathrm{Ct}}-1\right)}
$$


where $\mathrm{SD}_{\mathrm{Tx}}$ was the reported sample $\mathrm{SD}$ for side effects under treatment, $\mathrm{SD}_{\mathrm{Ct}}$ was the reported sample $\mathrm{SD}$ for side effects under control, $n_{\mathrm{Tx}}$ was the treatment sample size, and $n_{\mathrm{Ct}}$ the control sample size. The corresponding sampling variance $\left(s_{\log \mathrm{VR}}^{2}\right)$ for each comparison can be expressed as follows:

$$
s_{\log \mathrm{VR}}^{2}=\frac{1}{2\left(n_{\mathrm{Tx}}-1\right)}+\frac{1}{2\left(n_{\mathrm{Ct}}-1\right)}
$$

The individual variability ratios were weighted with the inverse of this sampling variance ${ }^{40}$ and entered into a randomeffects model to quantify the overall variability ratio of side effects. For better interpretability, results were backtransformed from the logarithmic scale. Here, a variability ratio greater than one would indicate a higher side effect variability in treatment compared to control, whereas a variability ratio smaller than one indicates less side effect variability under treatment compared with control.

\section{Data and code availability}

The analysis was performed from September 2019 to May 2020 , using the $\mathrm{R}$ package metafor ${ }^{40}$ (version 2.1.0). The manuscript was produced with the $\mathrm{R}$ packages rmarkdown (version 2.1); represearch (version 0.0.0.9000; https://github. com/phoman/represearch/); knitr (version 1.26); and papaja (version 0.1.0.9942). All data and code are freely available online to ensure reproducibility at https:/github.com/ homanlab/sideeffects/.

\section{Results}

\section{Overall reporting details}

Together, we screened $\mathrm{N}=151$ studies from the original metaanalysis by Huhn and colleagues ${ }^{6}$ as these studies reported data on at least one of the three side effects that we were interested in. Of these studies, $\mathrm{N}=94(62 \%)$ had missing variance measures despite reported means for at least one of the three side effects. We thus included the $\mathrm{N}=60(40 \%)$ studies that did report variance measures for at least one of the side effects of interest.

\section{Weight gain}

For weight gain, we included 51 RCTs, yielding 72 comparisons of antipsychotic drugs with placebo to investigate the individual occurrence of weight gain in patients. All together we included $\mathrm{N}=16578$ patients diagnosed with schizophrenia or schizoaffective disorder. There were 11373 (69\%) patients randomly allocated to the treatment group, and 5205 (31\%) to the placebo group. Overall, the variability for weight gain was higher under treatment than under control (VR $=1.08 ; 95 \%$ CI: $1.02-1.14 ; \mathrm{P}=0.004 ;$ Figure 1$)$. Individual comparisons between drugs across studies indicated marked differences between individual antipsychotics (VR = 1.08; 95\% CI: 1.02 - 1.14; P = 0.004; Figure 2).

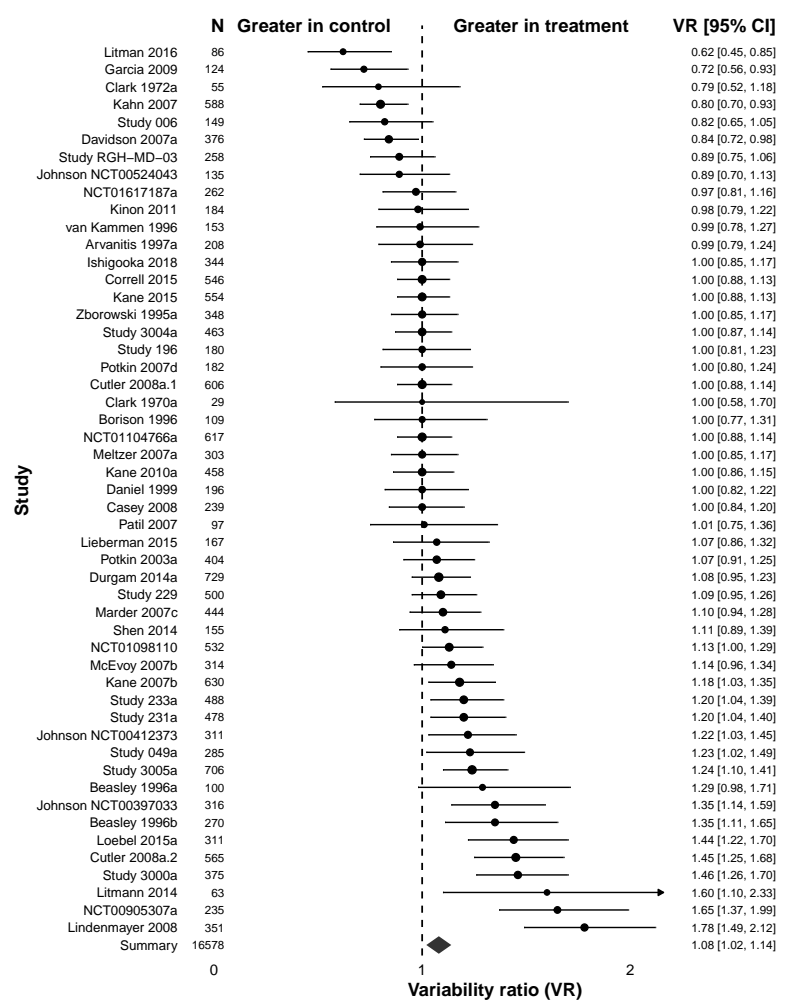

Figure 1. Variability ratio for weight gain. The forest plot shows the VR together with its $95 \%$ confidence interval (CI) for treatment versus control. All included studies ${ }^{41-93}$ are also listed in Table S1.

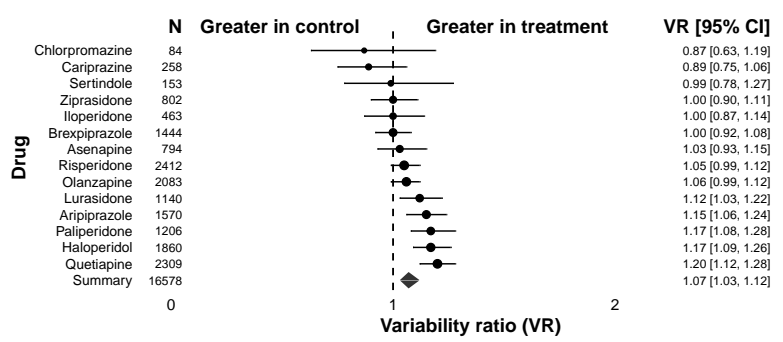

Figure 2. Variability ratio for weight gain for individual antipsychotics. The forest plot shows the VR together with its $95 \%$ confidence interval (CI) for treatment versus control. All included studies $^{41-93}$ are also listed in Table S1.

\section{Hyperprolactinemia}

For hyperprolactinemia, we included 50 RCTs, with 71 comparisons of antipsychotic drugs with placebo. All together we included $\mathrm{N}=16633$ patients diagnosed with schizophrenia or schizoaffective disorder. There were 11409 (69\%) patients randomly allocated to the treatment group, and 5224 (31\%) 
medRxiv preprint doi: https://doi.org/10.1101/2020.07.27.20162727; this version posted July 29, 2020. The copyright holder for this preprint (which was not certified by peer review) is the author/funder, who has granted medRxiv a license to display the preprint in perpetuity. All rights reserved. No reuse allowed without permission.

to the placebo group. Overall, the variability for hyperprolactinemia was higher under treatment than under control $(\mathrm{VR}=1.38 ; 95 \% \mathrm{CI}: 1.17$ - 1.62; $\mathrm{P}<0.001$; Figure 3$)$. Individual comparisons between drugs across studies indicated marked differences between individual antipsychotics (VR = 1.38; 95\% CI: 1.17 - 1.62; P < 0.001; Figure 4).

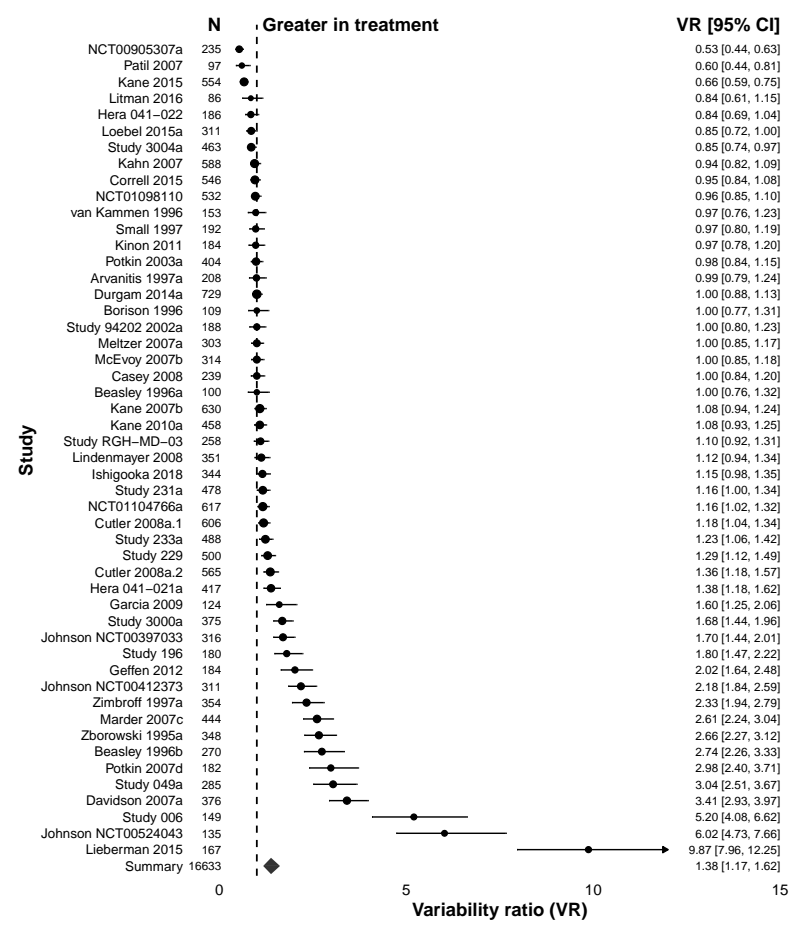

Figure 3. Variability ratio for hyperprolactinemia. The forest plot shows the VR together with its $95 \%$ confidence interval (CI) for treatment versus control. All included studies $^{41,42,44-48,50-58,60,62,64,65,67-69,72,74-79,82-90,92-100}$ are also listed in Table S1.
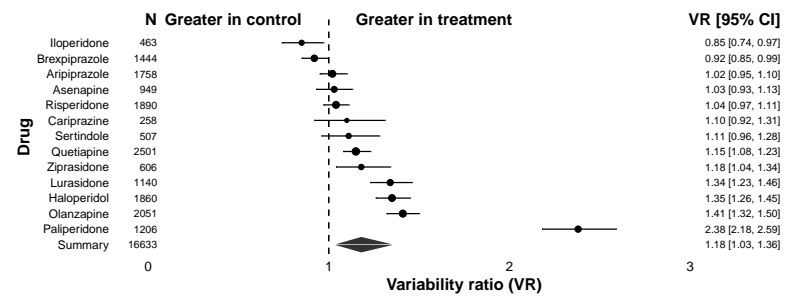

Figure 4. Variability ratio for hyperprolactinemia for individual antipsychotics. The forest plot shows the VR together with its $95 \%$ confidence interval (CI) for treatment versus control. All included studies $^{41,42,44-48,50-58,60,62,64,65,67-69,72,74-79,82-90,92-100}$ are also listed in Table S1.

\section{QTe prolongation}

For QTc prolongation, we included 29 RCTs, with 46 comparisons of antipsychotic drugs with placebo. All together we included $\mathrm{N}=10384$ patients diagnosed with schizophrenia or schizoaffective disorder. There were $7439(72 \%)$ patients randomly allocated to the treatment group, and $2945(28.00 \%)$ to the placebo group. Even though the variability for QTc prolongation was higher under treatment than under control, the difference did not reach statistical significance $(\mathrm{VR}=1.05$; 95\% CI: 0.98 - 1.12; $\mathrm{P}=0.135$; Figure 5).

However, individual comparisons between drugs across studies indicated marked differences between individual antipsychotics, with sertindole and haloperidol leading to significant increases in variability compared to control (VR $=1.05 ; 95 \%$ CI: $0.98-1.12 ; \mathrm{P}=0.135$; Figure 6).

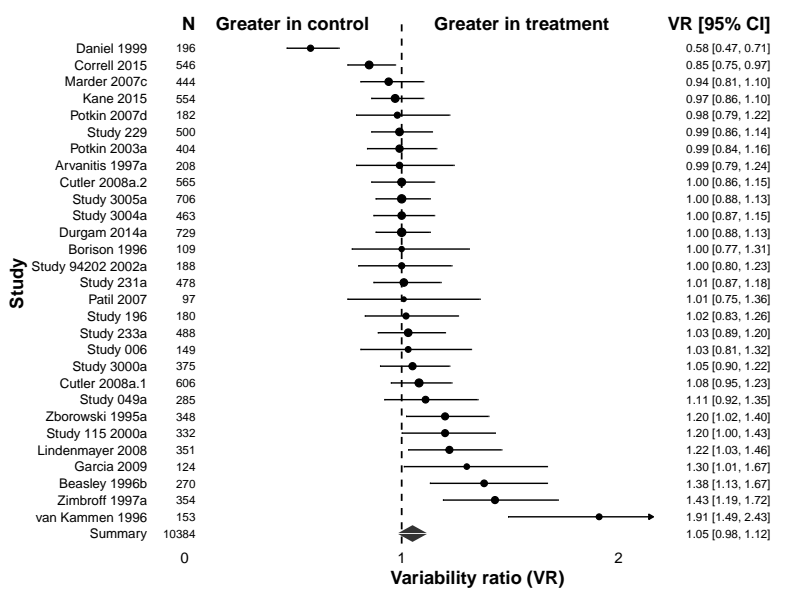

Figure 5. Variability ratio for QTc prolongation. The forest plot shows the VR together with its $95 \%$ confidence interval (CI) for treatment versus control. All included studies $^{42,45,51,52,54-60,62,68,70,74,76-80,85,86,89,93,94,99,100}$ are also listed in Table S1.

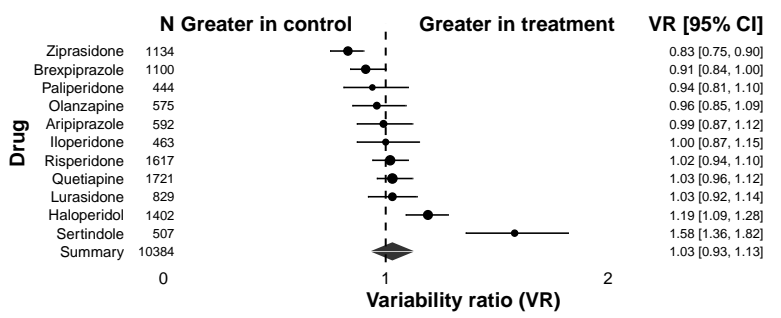

Figure 6. Variability ratio for QTC prolongation for individual antipsychotics. The forest plot shows the VR together with its $95 \%$ confidence interval (CI) for treatment versus control. All included studies $^{42,45,51,52,54-60,62,68,70,74,76-80,85,86,89,93,94,99,100}$ are also listed in Table S1.

\section{Discussion}

\section{Summary}

This study assessed the variability in the three major side effects of antipsychotic treatment in schizophrenia spectrum 
disorders. We focused on side effects because their occurrence has a great impact on treatment adherence and pyhsical health of patients, and clinical experience suggests a potential to improve treatment allocation by taking into account the variability in side effect occurrence. We wanted to quantify the evidence in support of this experience, relevant for clinicians as much as for translational researchers. We also know from clinical trials and meta-analyses that some antipsychotics are more associated with specific side effects than others. For example, clozapine and olanzapine are strongly associated with weight gain, ${ }^{6,20,101}$ QTc-time prolongation is most distinct in sertindole and amisulpride ${ }^{6}$, and prolactin level elevation in paliperidone and risperidone. ${ }^{6}$ However, these data cannot address the question whether there is variability in subgroups or individual patients. Such side effect-by-subgroup or side effect-by-patient interaction would be a prime example for the need of a more stratified or personalized medicine, respectively, which allocates treatments according to side effect profiles of subgroups or individual patients. The presence of such subgroups or individual patients would result in an increase of the side effect variability of treated patients compared to those who received placebo. ${ }^{7,13}$. The amount of this increase can be captured by the variability ratio (VR) which compares the variability of treatment versus control for each side effect. Evaluating all studies that reported variance measures for at least one of the investigated side effects, ${ }^{6}$ we found that the reporting of standard deviations was often incomplete. In terms of variability of side effects, we found that the variability for weight gain and prolactin elevation was indeed significantly increased in patients who received treatment compared to those who received placebo. For QTc prolongation, this increase was did not reach significance. Together, our results suggest that there is indeed marked variability in the occurrence of side effects in antipsychotic treatment.

\section{Reporting}

Altogether we included 43595 patients from 60 studies. Only for about $40 \%$ of studies included in a previous meta-analysis 6 variance data for at least one of the side effects of interest (weight gain, prolactin levels, QTc prolongation) were available. In about $62 \%$ of the studies included ${ }^{6}$ incomplete data existed such that means were reported without a measure of variance. Although we did contact authors for missing data whenever possible, we received missing data only for three studies. In summary, consistent reporting of antipsychotic side effects, specifically with respect to variability measures, is currently missing in the literature and should be improved in future studies.

\section{Weight gain}

Weight gain in antipsychotics, especially in second generation antipsychotics, ${ }^{102}$ is a severe side effect that can con- tribute to metabolic dysregulation. Importantly, every $\mathrm{kg}$ of weight gain leads to a linear increase in the risk of cardiovascular diseases ${ }^{22}$, heart failure ${ }^{21}$, and diabetes ${ }^{23}$. Clozapine, olanzapine, zotepine and sertindole have the most severe impact in gaining weight. Some studies showed that a lower BMI at baseline ${ }^{103}$ and $\operatorname{sex}^{104}$ can lead to more weight gain, whereas other studies found that male sex and higher BMI at baseline are related to a higher risk of metabolic distrubances. ${ }^{20}$ Our findings provide evidence that some patients are indeed more susceptible to antipsychotic weight gain than others. As antipsychotics in the treatment for schizophrenia and related diseases is often recommended to be taken as a relapse prevention for a longer period, ${ }^{105,106}$ patients are likely to gain more weight during their treatment over months and years. Together, this suggests that there is a potential to improve long-term health and adherence by identifying the subgroups or individual patients that are particularly prone to weight gain. Preliminary evidence suggests that a dysregulated striatal reward circuit contributes to weight gain susceptbility. ${ }^{5,107}$

\section{Hyperprolactinemia}

Prolactin level elevations occur in up to $70 \%$ of patients ${ }^{108}$ under the treatment with antipsychotic drugs. By blocking dopamine D2 receptors on lacotroph cells a disinhibition of the synthesis and secretion of prolactin is observed. ${ }^{109,110}$ This can lead to both, short- and long-term side effects with potentially severe impact on our patients health. Typical short time effects include galactorrhea, gynecomastia, menstrual irregularities, and sexual dysfunction; a typical long-term result is osteoporosis. ${ }^{111,112}$ and a potentially increased risk in developing breast cancer in association with hyperprolactinemia. ${ }^{113,114}$ Our findings suggest that these risks may be particularly relevant for some patients but not other patients. For example, a previous study found that prolactin level elevations are more pronounced and more frequent in women than in men. ${ }^{115}$ In addition, some antipsychotics such as amisulprid, risperidone, and paliperidone are linked to a greater elevation of prolactin. ${ }^{6,115}$ In summary, and in line with the weight gain findings, this suggests that there is a potential to improve long-term health and antipsychotic adherence by identifying the subgroups or individual patients that are particularly likely to develop prolactine elevations under antipsychotic treatment.

\section{QTc prolongation}

Prolongation of QTc is another important antipsychotic side effect as cardiovascular diseases remain the most common cause of natural mortality in schizophrenia spectrum disorders. ${ }^{116}$ Users of antipsychotic medication are reported to have higher rates of sudden cardiac death than nonusers. ${ }^{117}$ Prolongation of QTc (longer than $450 \mathrm{~ms}$ in men and longer than $470 \mathrm{~ms}$ in women, respectively, when 
corrected with Bazetts Formula ${ }^{118}$ ) can contribute to this. ${ }^{34}$ A prolongation of QTc can lead to torsade de pointes and subsequently to sudden death. ${ }^{119,120}$ The molecular pathway of this side effect is not completely understood. ${ }^{121}$ It is known, however, that some medications such as sertindole, amisulprid, ziprasidone lead to more QTc prolongation than others. ${ }^{6}$ Our findings suggest that although QTc prolongation varies between subgroups or patients this increased variability is not statistically significant, potentially because of a smaller number of studies available which decreased the statistical power. Previous studies suggest that risk factors may include female sex, comorbid cardiovascular disease, high drug dosages, and electrolyte disturbances. ${ }^{122}$

\section{Limitations and strengths}

Our meta-analysis had some limitations. First, the occurrence of side effects might be a dosage dependent effect, which could reflect a higher/different VR in some studies. Second, the level of prolactin can be highly variable based on multiple biological and methodological factors such as stress, diurnal variation and type of assay performed. This might explain the surprising difference in prolactin level variability between risperidone and paliperidone, two highly similar drugs. Third, for QTc, a reduced number of studies was available, potentially reducing statistical power to detect a significant variability increase. Finally, our method cannot determine whether the increased variability is due to variability differences in subgroups or individual patients. ${ }^{11}$. The particular strength of our study is that we included all available studies of antipsychotic treatment in SSD reporting variability measures for side effects of interest. To our knowledge, this is the first comprehensive study that provides evidence for substantial variability in side effects.

\section{Conclusion}

Our findings suggest that there is enough variability in two major side effects (weight gain and prolactin elevation) to assume that subgroups of patients or even individual patients may benefit from improved treatment allocation through stratified or personalized medicine, respectively. Such efforts in precision medicine might be crucial to improve adherence $^{123}$ and long-term health under antipsychotic treatment.

\section{Acknowledgements}

The authors thank Majnu John, $\mathrm{PhD}$, for advice on the analysis of the current study and Ellen $\mathrm{Ji}, \mathrm{PhD}$, for her thoughtful comments on the manuscript. These individuals received no additional compensation, outside of their usual salary, for their contributions.

\section{Funding/Support}

PH is supported by a NARSAD grant from the Brain \& Behavior Research Foundation (28445) and by a Research Grant from the Novartis Foundation (20A058).

\section{Conflict of interest}

In the last 3 years Dr. Leucht has received honoraria for service as a consultant or adviser and/or for lectures from Angelini, Böhringer Ingelheim, Geodon\&Richter, Janssen, Johnson\&Johnson, Lundbeck, LTS Lohmann, MSD, Otsuka, Recordati, SanofiAventis, Sandoz, Sunovion, TEVA. Dr. Kane reported grants from Otsuka, Lundbeck and Janssen, as well as other from Alkermes, Allergan, Forum, Genentech, Lundbeck, Intracellular Therapies, Janssen, Johnson \& Johnson, Merck, Neurocrine, Otsuka, Pierre Fabre, Reviva, Roche, Sunovion, Takeda, Teva, Vanguard Research Group, and LB Pharmaceuticals outside of the submitted work. No other disclosures were reported.

\section{References}

1. Lambert, M. et al. Impact of present and past antipsychotic side effects on attitude toward typical antipsychotic treatment and adherence. European Psychiatry 19, 415-422 (2004)

2. Kane, J. M., Kishimoto, T. \& Correll, C. U. Non-adherence to medication in patients with psychotic disorders: Epidemiology, contributing factors and management strategies. World Psychiatry 12, 216-226 (2013).

3. Sendt, K.-V., Tracy, D. K. \& Bhattacharyya, S. A systematic review of factors influencing adherence to antipsychotic medication in schizophrenia-spectrum disorders. Psychiatry Research 225, 14-30 (2015).

4. Wade, M., Tai, S., Awenat, Y. \& Haddock, G. A systematic review of service-user reasons for adherence and nonadherence to neuroleptic medication in psychosis. Clinical Psychology Review 51, 75-95 (2017).

5. Homan, P. et al. Striatal volume and functional connectivity correlate with weight gain in early-phase psychosis. Neuropsychopharmacology (2019).

6. Huhn, M. et al. Comparative efficacy and tolerability of 32 oral antipsychotics for the acute treatment of adults with multi-episode schizophrenia: A systematic review and network meta-analysis. The Lancet 394, 939-951 (2019).

7. Winkelbeiner, S., Leucht, S., Kane, J. M. \& Homan, P. Evaluation of Differences in Individual Treatment Response in Schizophrenia Spectrum Disorders: A Meta-analysis. FAMA Psychiatry (2019) doi:10.1001/jamapsychiatry.2019.1530.

8. Munkholm, K., Winkelbeiner, S. \& Homan, P. Individual response to antidepressants for depression in adults - a simulation study and meta-analysis. PsyArXiv (2019) doi:10.31219/osf.io/srzx5.

9. Senn, S. Mastering variation: Variance components and 
personalised medicine. Statistics in Medicine 35, 966-977 (2016).

10. Senn, S. Statistical pitfalls of personalized medicine. $\mathrm{Na}$ ture 563, 619-621 (2018).

11. Cortés, J. et al. Does evidence support the high expectations placed in precision medicine? A bibliographic review. F1000 Research 7, (2019).

12. Nakagawa, S. et al. Meta-analysis of variation: Ecological and evolutionary applications and beyond. Methods in Ecology and Evolution 6, 143-152 (2015).

13. Mills, H. L. et al. Detecting heterogeneity of intervention effects using analysis and meta-analysis of differences in variance between arms of a trial. MedRxiv (2020) doi:10.1101/2020.03.07.20032516.

14. Plöderl, M. \& Hengartner, M. P. What are the chances for personalised treatment with antidepressants? Detection of patient-by-treatment interaction with a variance ratio metaanalysis. BMf Open 9, (2019).

15. Volkmann, C. M. D., Volkmann, A. \& Mueller, C. On the treatment effect heterogeneity of antidepressants in major depression. a bayesian meta-analysis. MedRxiv (2020).

16. Winkelbeiner, S. et al. Treatment effect variation in brain stimulation across psychiatric disorders. MedRxiv (2020) doi:10.1101/2020.05.02.20088831.

17. Volkmann, A. On the relationship between treatment effect heterogeneity and the variability ratio effect size statistic. $\operatorname{arXiv}(2020)$.

18. Winkelbeiner, S. \& Homan, P. Is variance ratio a valid indicator of heterogeneous treatment effect?-reply. $\mathcal{F} A M A$ Psychiatry (2019) doi:10.1001/jamapsychiatry.2019.3382.

19. Homan, P. et al. Structural similarity networks predict clinical outcome in early-phase psychosis. Neuropsychopharmacology 44, 915-922 (2019).

20. Pillinger, T. et al. Comparative effects of 18 antipsychotics on metabolic function in patients with schizophrenia, predictors of metabolic dysregulation, and association with psychopathology: A systematic review and network metaanalysis. The Lancet Psychiatry 7, 64-77 (2020).

21. Kenchaiah, S. et al. Obesity and the risk of heart failure. New England Journal of Medicine 347, 305-313 (2002).

22. Willett, W. C. et al. Weight, weight change, and coronary heart disease in women. Risk within the 'normal' weight range. JAMA 273, 461-465 (1995).

23. Cooper, S. J. et al. BAP guidelines on the management of weight gain, metabolic disturbances and cardiovascular risk associated with psychosis and antipsychotic drug treatment. Journal of Psychopharmacology 30, 717-748 (2016).

24. Mustafa, S. et al. Predictors of 'all-cause discontinuation'of initial oral antipsychotic medication in first episode psychosis. Schizophrenia Research 201, 287-293 (2018).

25. Thapa, S. \& Bhusal, K. Hyperprolactinemia. in StatPearls (StatPearls Publishing, 2020).

26. Montejo, Á. L. et al. Frequency of sexual dysfunction in patients with a psychotic disorder receiving antipsychotics. Journal of Sexual Medicine 7, 3404-3413 (2010).

27. Serretti, A. \& Chiesa, A. A meta-analysis of sexual dysfunction in psychiatric patients taking antipsychotics. International Clinical Psychopharmacology 26, 130-140 (2011).

28. Heald, A. Physical health in schizophrenia: A challenge for antipsychotic therapy. European Psychiatry 25, S6-S11 (2010).

29. Homan, P., Kindler, J., Hauf, M., Hubl, D. \& Dierks, T. Cerebral blood flow identifies responders to transcranial magnetic stimulation in auditory verbal hallucinations. Translational Psychiatry 2, e189 (2012).

30. Cavelti, M. et al. Neuroimaging of formal thought disorder in schizophrenia: A systematic review. Schizoprenia Research 2-16 (2018).

31. Cavelti, M. et al. Formal thought disorder is related to aberrations in language-related white matter tracts in patients with schizophrenia. Psychiatry Research: Neuroimaging 40-50 (2018).

32. Winkelbeiner, S. et al. Decreased blood flow in the right insula and middle temporal gyrus predicts negative formal thought disorder in schizophrenia. Schizophrenia Research 201, 432-434 (2018).

33. Cavelti, M., Homan, P. \& Vauth, R. The impact of thought disorder on therapeutic alliance and personal recovery in schizophrenia and schizoaffective disorder: An exploratory study. Psychiatry Research 239, 92-98 (2016).

34. Funk, M. C. et al. QTc prolongation and psychotropic medications. The American fournal of Psychiatry 177, 273274 (2020).

35. Glassman, A. H. Schizophrenia, antipsychotic drugs, and cardiovascular disease. Fournal of Clinical Psychiatry 66, 510 (2005).

36. Vandael, E., Vandenberk, B., Vandenberghe, J., Willems, R. \& Foulon, V. Risk factors for qtc-prolongation: Systematic review of the evidence. International fournal of Clinical Pharmacy 39, 16-25 (2017).

37. Koponen, H. et al. Schizophrenia and sudden cardiac death-a review. Nordic fournal of Psychiatry 62, 342-345 (2008).

38. Tong, Z., Li, F., Ogawa, Y., Watanabe, N. \& Furukawa, T. A. Quality of randomized controlled trials of new generation antidepressants and antipsychotics identified in the china national knowledge infrastructure (cnki): A literature and telephone interview study. BMC Medical Research Methodology 18, (2018).

39. Hutton, B. et al. The PRISMA extension statement for reporting of systematic reviews incorporating network metaanalyses of health care interventions: Checklist and explanations. Annals of Internal Medicine 162, 777-784 (2015).

40. Viechtbauer, W. Conducting meta-analyses in $\mathrm{R}$ with the metafor package. Stat Software 36, 1-48 (2010).

41. Litman, R. E. et al. AZD8529, a positive allosteric modu- 
lator at the mGluR2 receptor, does not improve symptoms in schizophrenia: A proof of principle study. Schizophrenia Research 172, 152-157 (2016).

42. Garcia, E. et al. The efficacy and safety of blonanserin compared with haloperidol in acute-phase schizophrenia. CNS Drugs 23, 615-625 (2009).

43. Clark, M. L., Huber, W. K., Sullivan, J., Wood, F. \& Costiloe, J. P. Evaluation of loxapine succinate in chronic schizophrenia. Diseases of the Nervous System 33, 783-791 (1972).

44. Kahn, R. S. et al. Efficacy and tolerability of once-daily extended release quetiapine fumarate in acute schizophrenia: A randomized, double-blind, placebo-controlled study. Journal of Clinical Psychiatry 68, 832-842 (2007).

45. Ogasa, M., Kimura, T., Nakamura, M. \& Guarino, J. Lurasidone in the treatment of schizophrenia: A 6-week, placebocontrolled study. Psychopharmacology 225, 519-530 (2013). 46. Davidson, M. et al. Efficacy, safety and early response of paliperidone extended-release tablets (paliperidone ER): Results of a 6-week, randomized, placebo-controlled study. Schizophrenia Research 93, 117-130 (2007).

47. Durgam, S. et al. Cariprazine in the treatment of schizophrenia: A proof-of-concept trial. International Clinical Psychopharmacology 31, 61-68 (2016).

48. Coppola, D. et al. Efficacy and Safety of Paliperidone Extended Release $1.5 \mathrm{mg} /$ day-A Double-blind, Placeboand Active-Controlled, Study in the Treatment of Patients with Schizophrenia. Psychopharmacology Bulletin 44, 54-72 (2011).

49. Landbloom, R. et al. Asenapine for the treatment of adults with an acute exacerbation of schizophrenia: Results from a randomized, double-blind, fixed-dose, placebo-controlled trial with olanzapine as an active control. CNS Spectrums 22, 333-341 (2017).

50. Kinon, B. J. et al. A multicenter, inpatient, phase 2, doubleblind, placebo-controlled dose-ranging study of LY2140023 monohydrate in patients with DSM-IV schizophrenia. Fournal of Clinical Psychopharmacology 31, 349-355 (2011).

51. Kammen, D. P. van, McEvoy, J. P., Targum, S. D., Kardatzke, D. \& Sebree, T. B. A randomized, controlled, doseranging trial of sertindole in patients with schizophrenia. Psychopharmacology 124, 168-175 (1996).

52. Arvanitis, L. A. \& Miller, B. G. Multiple fixed doses of 'seroquel'(quetiapine) in patients with acute exacerbation of schizophrenia: A comparison with haloperidol and placebo. Biological Psychiatry 42, 233-246 (1997).

53. Ishigooka, J., Iwashita, S. \& Tadori, Y. Efficacy and safety of brexpiprazole for the treatment of acute schizophrenia in japan: A 6-week, randomized, double-blind, placebocontrolled study. Psychiatry and Clinical Neurosciences $\mathbf{7 2}$, 692-700 (2018).

54. Correll, C. U. et al. Efficacy and safety of brexpiprazole for the treatment of acute schizophrenia: A 6-week randomized, double-blind, placebo-controlled trial. The American fournal of Psychiatry 172, 870-880 (2015).

55. Zborowski, J. et al. Efficacy and safety of sertindole in a trial of schizophrenic patients. Biological Psychiatry 9, 661-662 (1995).

56. Potkin, S. G., Litman, R. E., Torres, R. \& Wolfgang, C. D. Efficacy of iloperidone in the treatment of schizophrenia: Initial phase 3 studies. Journal of Clinical Psychopharmacology 28, S4-11 (2008).

57. Nakamura, M. et al. Lurasidone in the treatment of acute schizophrenia: A double-blind, placebo-controlled trial. Journal of Clinical Psychiatry 70, 829-836 (2009).

58. Potkin, S. G., Cohen, M. \& Panagides, J. Efficacy and tolerability of asenapine in acute schizophrenia: A placebo-and risperidone-controlled trial. Journal of Clinical Psychiatry 68, 1492-1500 (2007).

59. Keck Jr, P. et al. Ziprasidone 40 and $120 \mathrm{mg} /$ day in the acute exacerbation of schizophrenia and schizoaffective disorder: A 4-week placebo-controlled trial. Psychopharmacology 140, 173-184 (1998).

60. Cutler, A. J. et al. A failed 6-week,randomized, doubleblind, placebo-controlled study of once-daily extended release quetiapine fumarate in patients with acute schizophrenia: Lessons learned. Psychopharmacology Bulletin 43, 37-69 (2010).

61. Clark, M. L., Huber, W. K., Sakata, K., Fowles, D. C. \& Serafetinides, E. A. Molindone in chronic schizophrenia. Clinical Pharmacology \& Therapeutics 11, 680-688 (1970).

62. Borison, R. L., Arvanitis, L. A. \& Milier, B. G. ICI 204,636, an atypical antipsychotic: Efficacy and safety in a multicenter, placebo-controlled trial in patients with schizophrenia. Journal of Clinical Psychopharmacology 16, 158-169 (1996). 63. Ahmed, S. et al. Lipid profile among patients with schizophrenia randomized to bifeprunox, placebo, or olanzapine: A comparison of results. Schizophrenia Bulletin 33, 417-417 (2007).

64. Durgam, S. et al. Cariprazine in acute exacerbation of schizophrenia: A fixed-dose, phase 3, randomized, doubleblind, placebo-and active-controlled trial. Fournal of Clinical Psychiatry 76, e1574-82 (2015).

65. Meltzer, H., Barbato, L., Heisterberg, J., Yeung, P. \& Shapira, N. A randomized, double-blind, placebo-controlled efficacy and safety study of bifeprunox as treatment for patients with acutely exacerbated schizophrenia. Schizophrenia Bulletin 33, 446-446 (2007).

66. Meltzer, H. Y., Arvanitis, L., Bauer, D., Rein, W. \& Group, M.-T. S. Placebo-controlled evaluation of four novel compounds for the treatment of schizophrenia and schizoaffective disorder. The American fournal of Psychiatry 161, 975$984(2004)$.

67. Kane, J. M., Cohen, M., Zhao, J., Alphs, L. \& Panagides, J. Efficacy and safety of asenapine in a placebo-and haloperidolcontrolled trial in patients with acute exacerbation of schizophrenia. Journal of Clinical Psychopharmacology 30, 
106-115 (2010).

68. Kane, J. M. et al. Efficacy and safety of aripiprazole and haloperidol versus placebo in patients with schizophrenia and schizoaffective disorder. The fournal of Clinical Psychiatry 63, 763-771 (2002).

69. Hirayasu, Y., Tomioka, M., Iizumi, M. \& Kikuchi, H. A double-blind, placebo-controlled, comparative study of paliperidone extended release (er) tablets in patients with schizophrenia. Japanese fournal of Psychopharmacology 13, 2077-2103 (2010).

70. Daniel, D. G. et al. Ziprasidone $80 \mathrm{mg} /$ day and $160 \mathrm{mg} /$ day in the acute exacerbation of schizophrenia and schizoaffective disorder: A 6-week placebo-controlled trial. Neuropsychopharmacology 20, 491-505 (1999).

71. Cooper, S., Tweed, J., Raniwalla, J., Butler, A. \& Welch, C. A placebo-controlled comparison of zotepine versus chlorpromazine in patients with acute exacerbation of schizophrenia. Acta Psychiatrica Scandinavica 101, 218-225 (2000).

72. Casey, D. E., Sands, E. E., Heisterberg, J. \& Yang, H.-M. Efficacy and safety of bifeprunox in patients with an acute exacerbation of schizophrenia: Results from a randomized, double-blind, placebo-controlled, multicenter, dose-finding study. Psychopharmacology 200, 317-331 (2008).

73. Bugarski-Kirola, D., Wang, A., Abi-Saab, D. \& Blättler, T. A phase ii/iii trial of bitopertin monotherapy compared with placebo in patients with an acute exacerbation of schizophrenia-results from the candlelyte study. European Neuropsychopharmacology 24, 1024-1036 (2014).

74. Patil, S. T. et al. Activation of $m G l u 2 / 3$ receptors as a new approach to treat schizophrenia: A randomized Phase 2 clinical trial. Nature Medicine 13, 1102-1107 (2007).

75. Lieberman, J. A. et al. ITI-007 for the Treatment of Schizophrenia: A 4-Week Randomized, DoubleBlind, Controlled Trial. Biological Psychiatry (2015) doi:10.1016/j.biopsych.2015.08.026.

76. Potkin, S. G. et al. Aripiprazole, an antipsychotic with a novel mechanism of action, and risperidone vs placebo in patients with schizophrenia and schizoaffective disorder. Archives of General Psychiatry 60, 681-690 (2003).

77. Durgam, S. et al. An evaluation of the safety and efficacy of cariprazine in patients with acute exacerbation of schizophrenia: A phase II, randomized clinical trial. Schizophrenia Research 152, 450-457 (2014).

78. Nasrallah, H. A. et al. Lurasidone for the treatment of acutely psychotic patients with schizophrenia: A 6-week, randomized, placebo-controlled study. Fournal of Psychiatric Research 47, 670-677 (2013).

79. Marder, S. R. et al. Efficacy and safety of paliperidone extended-release tablets: Results of a 6-week, randomized, placebo-controlled study. Biological Psychiatry 62, 1363-1370 (2007).

80. Borison, R. L., Pathiraja, A. P., Diamond, B. I. \& Meibach, R. C. Risperidone: Clinical safety and efficacy in schizophre- nia. Psychopharmacology Bulletin (1992).

81. Shen, J. H. Q. et al. A 6-week randomized, double-blind, placebo-controlled, comparator referenced trial of vabicaserin in acute schizophrenia. Fournal of Psychiatric Research 53, 14-22 (2014).

82. Kinoshita, T., Bai, Y.-M., Kim, J.-H., Miyake, M. \& Oshima, N. Efficacy and safety of asenapine in Asian patients with an acute exacerbation of schizophrenia: A multicentre, randomized, double-blind, 6-week, placebo-controlled study. Psychopharmacology 233, 2663-2674 (2016).

83. McEvoy, J. P., Daniel, D. G., Carson, W. H., McQuade, R. D. \& Marcus, R. N. A randomized, double-blind, placebocontrolled, study of the efficacy and safety of aripiprazole 10 , 15 or $20 \mathrm{mg} /$ day for the treatment of patients with acute exacerbations of schizophrenia. Journal of Psychiatric Research 41, 895-905 (2007).

84. Kane, J. et al. Treatment of schizophrenia with paliperidone extended-release tablets: A 6-week placebo-controlled trial. Schizophrenia Research 90, 147-161 (2007).

85. Harvey, P. D., Loebel, A., Cucchiaro, J., Phillips, D. \& $\mathrm{Siu}, \mathrm{C}$. Is quality of life related to cognitive performance or negative symptoms in patients with schizophrenia? Results from a double-blind, active-controlled, lurasidone extension study. Neuropsychopharmacology 38, S515-S515 (2013).

86. Meltzer, H. Y. et al. Lurasidone in the treatment of schizophrenia: A randomized, double-blind, placebo- and olanzapine-controlled study. American fournal of Psychiatry 168, 957-967 (2011).

87. Beasley, C. M. et al. Olanzapine versus placebo: Results of a double-blind, fixed-dose olanzapine trial. Psychopharmacology 124, 159-167 (1996).

88. Canuso, C. M. et al. A randomized, double-blind, placebocontrolled study of 2 dose ranges of paliperidone extendedrelease in the treatment of subjects with schizoaffective disorder. Journal of Clinical Psychiatry 71, 587-598 (2010).

89. Beasley, C. M. et al. Olanzapine versus placebo and haloperidol: Acute phase results of the North American double-blind olanzapine trial. Neuropsychopharmacology 14, 111-123 (1996).

90. Loebel, A. et al. Lurasidone Dose Escalation in Early Nonresponding Patients With Schizophrenia: A Randomized, Placebo-Controlled Study. Fournal of Clinical Psychiatry 77, 1672-1680 (2016).

91. Litman, R. E. et al. The selective neurokinin 3 antagonist AZD2624 does not improve symptoms or cognition in schizophrenia: A proof-of-principle study. Fournal of Clinical Psychopharmacology 34, 199-204 (2014).

92. Kane, J. M. et al. Overview of short- and long-term tolerability and safety of brexpiprazole in patients with schizophrenia. Schizophrenia Research 174, 93-98 (2016).

93. Lindenmayer, J.-P., Brown, D., Liu, S., Brecher, M. \& Meulien, D. The efficacy and tolerability of once-daily extended release quetiapine fumarate in hospitalized patients 
with acute schizophrenia: A 6-week randomized, doubleblind, placebo-controlled study. Psychopharmacology Bulletin 41, 11-35 (2008).

94. Kane, J. M. et al. A multicenter, randomized, double-blind, controlled phase 3 trial of fixed-dose brexpiprazole for the treatment of adults with acute schizophrenia. Schizophrenia Research 164, 127-135 (2015).

95. Small, J. G., Hirsch, S. R., Arvanitis, L. A., Miller, B. G. \& Link, C. G. Quetiapine in patients with schizophrenia: A high-and low-dose double-blind comparison with placebo. Archives of General Psychiatry 54, 549-557 (1997).

96. Schmidt, M. E. et al. A double-blind, randomized, placebocontrolled study with jnj-37822681, a novel, highly selective, fast dissociating $\mathrm{d} 2$ receptor antagonist in the treatment of acute exacerbation of schizophrenia. European Neuropsychopharmacology 22, 721-733 (2012).

97. Geffen, Y., Keefe, R., Rabinowitz, J., Anand, R. \& Davidson, M. Bl-1020, a new $\gamma$-aminobutyric acid-enhanced antipsychotic: Results of 6-week, randomized, double-blind, controlled, efficacy and safety study. Fournal of Clinical Psychiatry 73, e1168-74 (2012).

98. Canuso, C. M. et al. Paliperidone extended-release in schizoaffective disorder: A randomized, controlled study comparing a flexible dose with placebo in patients treated with and without antidepressants and/or mood stabilizers. Journal of Clinical Psychopharmacology 30, 487-495 (2010). 99. Zimbroff, D. L. et al. Controlled, dose-response study of sertindole and haloperidol in the treatment of schizophrenia. The American fournal of Psychiatry 154, 782-791 (1997).

100. Potkin, S. G., Kimura, T. \& Guarino, J. A 6-week, doubleblind, placebo- and haloperidol-controlled, phase II study of lurasidone in patients with acute schizophrenia. Therapeutic Advances in Psychopharmacology 5, 322-331 (2015).

101. Homan, P. \& Kane, J. M. Clozapine as an early-stage treatment. Acta Psychiatrica Scandinavica 138, 279-280 (2018).

102. Osborn, D. P. et al. Weight change over two years in people prescribed olanzapine, quetiapine and risperidone in UK primary care: Cohort study in THIN, a UK primary care database. The fournal of Psychopharmacology 32, 1098-1103 (2018).

103. Gebhardt, S. et al. Antipsychotic-induced body weight gain: Predictors and a systematic categorization of the longterm weight course. Fournal of Psychiatric Research 43, 620626 (2009).

104. Najar, H., Joas, E., Kardell, M., Pålsson, E. \& Landén, M. Weight gain with add-on second-generation antipsychotics in bipolar disorder: A naturalistic study. Acta Psychiatrica Scandinavica 135, 606-611 (2017).

105. Leucht, S. et al. Maintenance treatment with antipsychotic drugs for schizophrenia. Cochrane Database of Systematic Reviews (2012) doi:10.1002/14651858.CD008016.pub2. 106. Homan, P. et al. Relapse prevention through health technology program reduces hospitalization in schizophrenia.
bioRxiv (2019).

107. Nielsen, M., Rostrup, E., Wulff, S., Glenthoj, B. \& Ebdrup, B. H. Striatal reward activity and antipsychotic-associated weight change in patients with schizophrenia undergoing initial treatment. JAMA Psychiatry 73, 121-128 (2016).

108. Inder, W. J. \& Castle, D. Antipsychotic-Induced Hyperprolactinaemia: Australian and New Zealand Journal of Psychiatry (2011).

109. Ben-Jonathan, N. \& Hnasko, R. Dopamine as a prolactin (PRL) inhibitor. Endocrine Reviews 22, 724-763 (2001).

110. Bushe, C. J., Bradley, A. \& Pendlebury, J. A review of hyperprolactinaemia and severe mental illness: Are there implications for clinical biochemistry? Annals of Clinical Biochemistry 47, 292-300 (2010).

111. Mazziotti, G., Frara, S. \& Giustina, A. Pituitary Diseases and Bone. Endocrine Reviews 39, 440-488 (2018).

112. Byerly, M., Suppes, T., Tran, Q.-V. \& Baker, R. A. Clinical Implications of Antipsychotic-Induced Hyperprolactinemia in Patients With Schizophrenia Spectrum or Bipolar Spectrum Disorders: Recent Developments and Current Perspectives. Fournal of Clinical Psychopharmacology 27, 639-661 (2007).

113. Johnston, A. N. et al. Hyperprolactinemia-inducing antipsychotics increase breast cancer risk by activating JAKSTAT5 in precancerous lesions. Breast Cancer Research 20, 42 (2018).

114. George, A. et al. Psychotropic Medication Use and Postmenopausal Breast Cancer Risk. Cancer Epidemiology, Biomarkers \& Prevention 29, 254-256 (2020).

115. Veselinović, T. et al. Impact of different antidopaminergic mechanisms on the dopaminergic control of prolactin secretion. Journal of Clinical Psychopharmacology 31, 214220 (2011).

116. Riordan, H. J., Antonini, P. \& Murphy, M. F. Atypical Antipsychotics and Metabolic Syndrome in Patients with Schizophrenia: Risk Factors, Monitoring, and Healthcare Implications. American Health \& Drug Benefits 4, 292-302 (2011).

117. Ray, W. A., Chung, C. P., Murray, K. T., Hall, K. \& Stein, C. M. Atypical Antipsychotic Drugs and the Risk of Sudden Cardiac Death. New England Journal of Medicine (2009) doi:10.1056/NEJMoa0806994.

118. Bazett, H. C. An Analysis of the Time-Relations of Electrocardiograms. Annals of Noninvasive Electrocardiology 2, 177-194 (1997).

119. Glassman, A. H. \& Bigger, J. T. Antipsychotic Drugs: Prolonged QTc Interval, Torsade de Pointes, and Sudden Death. The American Journal of Psychiatry 158, 1774-1782 (2001).

120. Nielsen, J. et al. Assessing QT Interval Prolongation and its Associated Risks with Antipsychotics. CNS Drugs 25, 473-490 (2011).

121. Spellmann, I. et al. QTc prolongation in short-term treat- 
ment of schizophrenia patients: Effects of different antipsychotics and genetic factors. European Archives of Psychiatry and Clinical Neuroscience 268, 383-390 (2018).

122. Lindström, E., Farde, L., Eberhard, J. \& Haverkamp, W. QTc interval prolongation and antipsychotic drug treatments: Focus on sertindole. International fournal of Neuropsychopharmacology 8, 615-629 (2005).

123. Zullig, L. L. et al. The new landscape of medication adherence improvement: Where population health science meets precision medicine. Patient Preference and Adherence (2018) doi:10.2147/PPA.S165404.

124. Kane, J. M. et al. Efficacy and safety of cariprazine in acute exacerbation of schizophrenia: Results from an international, phase iii clinical trial. Fournal of Clinical Psychopharmacology 35, 367-373 (2015).

125. Center for Drug Evaluation and Research. A multicenter, randomized, double-blind, fixed-dose, 6-week trial of the efficacy and safety of asenapine compared with placebo using olanzapine postive control in subjects with an acute exacerbation of schizophrenia. Medical Reviews 22-117 (2009).

126. Center for Drug Evaluation and Research. A multicenter, randomized, double-blind, flexible-dose, 6-week trial of the efficacy and safety of asenapine compared with placebo using olanzapine postive control in subjects with an acute exacerbation of schizophrenia. Medical Reviews 23-117 (2009).

127. Center for Drug Evaluation and Research. Study 9420 2002. Medical Reviews S9, 21-436 (2002).

128. Center for Drug Evaluation and Research. Study 115 2000. Medical Reviews S1, 20-825 (2000). 
medRxiv preprint doi: https://doi.org/10.1101/2020.07.27.20162727; this version posted July 29, 2020. The copyright holder for this preprint (which was not certified by peer review) is the author/funder, who has granted medRxiv a license to display the preprint in perpetuity.

All rights reserved. No reuse allowed without permission.

12

\section{Supplementary Information}

\section{Supplementary Tables}

Table S1

All study arms with references

\begin{tabular}{|c|c|c|c|c|c|c|}
\hline Study Arm & Year & Sample Size & Drug & Weight & Prolactin & $\overline{Q T c}$ \\
\hline Ishigooka $2018^{53}$ & 2018 & 116 & Placebo & Yes & Yes & No \\
\hline Ishigooka $2018^{53}$ & 2018 & 228 & Brexpiprazole & Yes & Yes & No \\
\hline Litman $2016^{41}$ & 2016 & 55 & Placebo & Yes & Yes & No \\
\hline Litman $2016^{41}$ & 2016 & 31 & Risperidone & Yes & Yes & No \\
\hline NCT01104766a ${ }^{64}$ & 2015 & 153 & Placebo & Yes & Yes & No \\
\hline NCT01104766a $a^{64}$ & 2015 & 152 & Aripiprazole & Yes & Yes & No \\
\hline NCT01104766b 64 & 2015 & 312 & Cariprazine & Yes & Yes & No \\
\hline Lieberman $2015^{75}$ & 2015 & 85 & Placebo & Yes & Yes & No \\
\hline Lieberman $2015^{75}$ & 2015 & 82 & Risperidone & Yes & Yes & No \\
\hline Kane $2015^{124}$ & 2015 & 184 & Placebo & Yes & Yes & Yes \\
\hline Kane $2015^{124}$ & 2015 & 370 & Brexpiprazole & Yes & Yes & Yes \\
\hline Correll $2015^{54}$ & 2015 & 184 & Placebo & Yes & Yes & Yes \\
\hline Correll $2015^{54}$ & 2015 & 362 & Brexpiprazole & Yes & Yes & Yes \\
\hline NCT01098110 82 & 2015 & 174 & Placebo & Yes & Yes & No \\
\hline NCT01098110 82 & 2015 & 358 & Asenapine & Yes & Yes & No \\
\hline NCT01617187a $a^{49}$ & 2015 & 113 & Asenapine & Yes & No & No \\
\hline NCT01617187a $a^{49}$ & 2015 & 103 & Placebo & Yes & No & No \\
\hline NCT01617187b ${ }^{49}$ & 2015 & 46 & Olanzapine & Yes & No & No \\
\hline NCT00905307a92 & 2015 & 50 & Aripiprazole & Yes & Yes & No \\
\hline NCT00905307a 92 & 2015 & 95 & Placebo & Yes & Yes & No \\
\hline NCT00905307b 92 & 2015 & 90 & Brexpiprazole & Yes & Yes & No \\
\hline Loebel 2015a $\mathrm{a}^{90}$ & 2015 & 199 & Lurasidone & Yes & Yes & No \\
\hline Loebel $2015 \mathrm{a}^{90}$ & 2015 & 112 & Placebo & Yes & Yes & No \\
\hline Litmann $2014^{91}$ & 2014 & 41 & Placebo & Yes & No & No \\
\hline Litmann $2014^{91}$ & 2014 & 22 & Olanzapine & Yes & No & No \\
\hline Schmidt $2014^{96}$ & 2014 & 93 & Olanzapine & Yes & Yes & No \\
\hline Shen $2014^{81}$ & 2014 & 78 & Placebo & Yes & No & No \\
\hline Shen $2014^{81}$ & 2014 & 77 & Olanzapine & Yes & No & No \\
\hline Durgam $2014 a^{77}$ & 2014 & 151 & Placebo & Yes & Yes & Yes \\
\hline Durgam $2014 \mathrm{a}^{77}$ & 2014 & 140 & Risperidone & Yes & Yes & Yes \\
\hline Durgam $2014 b^{77}$ & 2014 & 438 & Cariprazine & Yes & Yes & Yes \\
\hline Geffen $2012^{97}$ & 2012 & 91 & Risperidone & No & Yes & No \\
\hline Geffen $2012^{97}$ & 2012 & 93 & Placebo & No & Yes & No \\
\hline Kinon $2011^{50}$ & 2011 & 62 & Olanzapine & Yes & Yes & No \\
\hline Kinon $2011^{50}$ & 2011 & 122 & Placebo & Yes & Yes & No \\
\hline Kane $2010 a^{67}$ & 2010 & 115 & Haloperidol & Yes & Yes & No \\
\hline Kane $2010 a^{67}$ & 2010 & 123 & Placebo & Yes & Yes & No \\
\hline Kane $2010 b^{67}$ & 2010 & 220 & Asenapine & Yes & Yes & No \\
\hline Study $006^{45}$ & 2010 & 99 & Lurasidone & Yes & Yes & Yes \\
\hline Study $006^{45}$ & 2010 & 50 & Placebo & Yes & Yes & Yes \\
\hline Study $049 a^{100}$ & 2010 & 73 & Haloperidol & Yes & Yes & Yes \\
\hline Study $049 a^{100}$ & 2010 & 72 & Placebo & Yes & Yes & Yes \\
\hline Study $049 b^{100}$ & 2010 & 140 & Lurasidone & Yes & Yes & Yes \\
\hline Study $196^{57}$ & 2010 & 90 & Placebo & Yes & Yes & Yes \\
\hline Study $196^{57}$ & 2010 & 90 & Lurasidone & Yes & Yes & Yes \\
\hline Study $229^{78}$ & 2010 & 372 & Lurasidone & Yes & Yes & Yes \\
\hline
\end{tabular}




\begin{tabular}{|c|c|c|c|c|c|c|}
\hline Study Arm & Year & Sample Size & Drug & Weight & Prolactin & $\overline{\mathrm{QTc}}$ \\
\hline Study $229^{78}$ & 2010 & 128 & Placebo & Yes & Yes & $\overline{\text { Yes }}$ \\
\hline Study $231 a^{86}$ & 2010 & 116 & Placebo & Yes & Yes & Yes \\
\hline Study $231 a^{86}$ & 2010 & 123 & Olanzapine & Yes & Yes & Yes \\
\hline Study $231 b^{86}$ & 2010 & 239 & Lurasidone & Yes & Yes & Yes \\
\hline Study $233 \mathrm{a}^{85}$ & 2010 & 122 & Placebo & Yes & Yes & Yes \\
\hline Study $233 \mathrm{a}^{85}$ & 2010 & 120 & Quetiapine & Yes & Yes & Yes \\
\hline Study $233 b^{85}$ & 2010 & 246 & Lurasidone & Yes & Yes & Yes \\
\hline Garcia $2009^{42}$ & 2009 & 60 & Haloperidol & Yes & Yes & Yes \\
\hline Garcia $2009^{42}$ & 2009 & 64 & Placebo & Yes & Yes & Yes \\
\hline Hera $041-021 a^{125}$ & 2009 & 208 & Asenapine & No & Yes & No \\
\hline Hera $041-021 a^{125}$ & 2009 & 106 & Placebo & No & Yes & No \\
\hline Hera $041-021 b^{125}$ & 2009 & 103 & Olanzapine & No & Yes & No \\
\hline Hera $041-022^{126}$ & 2009 & 93 & Olanzapine & No & Yes & No \\
\hline Hera $041-022^{126}$ & 2009 & 93 & Placebo & No & Yes & No \\
\hline Casey $2008^{72}$ & 2008 & 120 & Risperidone & Yes & Yes & No \\
\hline Casey $2008^{72}$ & 2008 & 119 & Placebo & Yes & Yes & No \\
\hline Cutler $2008 \mathrm{a}^{60}$ & 2008 & 151 & Ziprasidone & Yes & Yes & Yes \\
\hline Cutler 2008a $\mathrm{a}^{60}$ & 2008 & 152 & Placebo & Yes & Yes & Yes \\
\hline Cutler $2008 b^{60}$ & 2008 & 303 & Iloperidone & Yes & Yes & Yes \\
\hline Johnson NCT0039703388 & 2008 & 209 & Paliperidone & Yes & Yes & No \\
\hline Johnson NCT00397033 88 & 2008 & 107 & Placebo & Yes & Yes & No \\
\hline Johnson NCT00412373 98 & 2008 & 95 & Placebo & Yes & Yes & No \\
\hline Johnson NCT0041237398 & 2008 & 216 & Paliperidone & Yes & Yes & No \\
\hline Johnson NCT00524043 ${ }^{48}$ & 2008 & 70 & Paliperidone & Yes & Yes & No \\
\hline Johnson NCT00524043 ${ }^{48}$ & 2008 & 65 & Placebo & Yes & Yes & No \\
\hline Lindenmayer $2008^{93}$ & 2008 & 267 & Quetiapine & Yes & Yes & Yes \\
\hline Lindenmayer $2008^{93}$ & 2008 & 84 & Placebo & Yes & Yes & Yes \\
\hline Study $3000 a^{56}$ & 2008 & 127 & Placebo & Yes & Yes & Yes \\
\hline Study $3000 a^{56}$ & 2008 & 124 & Haloperidol & Yes & Yes & Yes \\
\hline Study $3000 b^{56}$ & 2008 & 124 & Iloperidone & Yes & Yes & Yes \\
\hline Study $3004 a^{56}$ & 2008 & 156 & Placebo & Yes & Yes & Yes \\
\hline Study $3004 a^{56}$ & 2008 & 154 & Iloperidone & Yes & Yes & Yes \\
\hline Study $3004 b^{56}$ & 2008 & 153 & Risperidone & Yes & Yes & Yes \\
\hline Study $3005 a^{56}$ & 2008 & 157 & Risperidone & Yes & No & Yes \\
\hline Study $3005 a^{56}$ & 2008 & 160 & Placebo & Yes & No & Yes \\
\hline Study $3005 b^{56}$ & 2008 & 389 & Iloperidone & Yes & No & Yes \\
\hline Study RGH-MD- $03^{47}$ & 2008 & 130 & Placebo & Yes & Yes & No \\
\hline Study RGH-MD- $03^{47}$ & 2008 & 128 & Cariprazine & Yes & Yes & No \\
\hline Cutler $2008 \mathrm{a}^{60}$ & 2008 & 117 & Placebo & Yes & Yes & Yes \\
\hline Cutler $2008 \mathrm{a}^{60}$ & 2008 & 448 & Quetiapine & Yes & Yes & Yes \\
\hline Davidson $2007 \mathrm{a}^{46}$ & 2007 & 123 & Placebo & Yes & Yes & No \\
\hline Davidson $2007 \mathrm{a}^{46}$ & 2007 & 128 & Olanzapine & Yes & Yes & No \\
\hline Davidson $2007 b^{46}$ & 2007 & 125 & Paliperidone & Yes & Yes & No \\
\hline Kahn $2007^{44}$ & 2007 & 118 & Placebo & Yes & Yes & No \\
\hline Kahn $2007^{44}$ & 2007 & 470 & Quetiapine & Yes & Yes & No \\
\hline McEvoy $2007 b^{83}$ & 2007 & 206 & Aripiprazole & Yes & Yes & No \\
\hline McEvoy $2007 b^{83}$ & 2007 & 108 & Placebo & Yes & Yes & No \\
\hline Meltzer $2007 a^{65}$ & 2007 & 149 & Placebo & Yes & Yes & No \\
\hline Meltzer $2007 a^{65}$ & 2007 & 154 & Risperidone & Yes & Yes & No \\
\hline Kane $2007 b^{84}$ & 2007 & 127 & Placebo & Yes & Yes & No \\
\hline Kane $2007 b^{84}$ & 2007 & 128 & Olanzapine & Yes & Yes & No \\
\hline Kane $2007 \mathrm{c}^{84}$ & 2007 & 375 & Paliperidone & Yes & Yes & No \\
\hline
\end{tabular}




\begin{tabular}{|c|c|c|c|c|c|c|}
\hline Study Arm & Year & Sample Size & Drug & Weight & Prolactin & QTc \\
\hline Marder $2007 c^{79}$ & 2007 & 110 & Placebo & Yes & Yes & Yes \\
\hline Marder $2007 \mathrm{c}^{79}$ & 2007 & 224 & Paliperidone & Yes & Yes & Yes \\
\hline Marder $2007 d^{79}$ & 2007 & 110 & Olanzapine & Yes & Yes & Yes \\
\hline Patil $2007^{74}$ & 2007 & 34 & Olanzapine & Yes & Yes & Yes \\
\hline Patil $2007^{74}$ & 2007 & 63 & Placebo & Yes & Yes & Yes \\
\hline Potkin $2007 \mathrm{~d}^{58}$ & 2007 & 62 & Placebo & Yes & Yes & Yes \\
\hline Potkin $2007 d^{58}$ & 2007 & 60 & Risperidone & Yes & Yes & Yes \\
\hline Potkin $2007 c^{58}$ & 2007 & 60 & Asenapine & Yes & Yes & Yes \\
\hline Potkin $2003 \mathrm{a}^{76}$ & 2003 & 202 & Aripiprazole & Yes & Yes & Yes \\
\hline Potkin $2003 \mathrm{a}^{76}$ & 2003 & 103 & Placebo & Yes & Yes & Yes \\
\hline Potkin $2003 b^{76}$ & 2003 & 99 & Risperidone & Yes & Yes & Yes \\
\hline Kane $2002 b^{68}$ & 2002 & 104 & Haloperidol & Yes & Yes & Yes \\
\hline Study $942022002 a^{127}$ & 2002 & 61 & Aripiprazole & No & Yes & Yes \\
\hline Study $942022002 a^{127}$ & 2002 & 64 & Placebo & No & Yes & Yes \\
\hline Study $942022002 b^{127}$ & 2002 & 63 & Haloperidol & No & Yes & Yes \\
\hline Study $1152000 a^{128}$ & 2000 & 83 & Placebo & No & No & Yes \\
\hline Study $1152000 a^{128}$ & 2000 & 164 & Ziprasidone & No & No & Yes \\
\hline Study $1152000 b^{128}$ & 2000 & 85 & Haloperidol & No & No & Yes \\
\hline Daniel $1999^{70}$ & 1999 & 92 & Placebo & Yes & No & Yes \\
\hline Daniel $1999^{70}$ & 1999 & 104 & Ziprasidone & Yes & No & Yes \\
\hline Arvanitis $1997 a^{52}$ & 1997 & 51 & Placebo & Yes & Yes & Yes \\
\hline Arvanitis $1997 \mathrm{a}^{52}$ & 1997 & 105 & Quetiapine & Yes & Yes & Yes \\
\hline Arvanitis $1997 b^{52}$ & 1997 & 52 & Haloperidol & Yes & Yes & Yes \\
\hline Small $1997^{95}$ & 1997 & 96 & Quetiapine & No & Yes & No \\
\hline Small $1997^{95}$ & 1997 & 96 & Placebo & No & Yes & No \\
\hline Zimbroff 1997a ${ }^{99}$ & 1997 & 144 & Sertindole & No & Yes & Yes \\
\hline Zimbroff 1997a 99 & 1997 & 73 & Placebo & No & Yes & Yes \\
\hline Zimbroff $1997 b^{99}$ & 1997 & 137 & Haloperidol & No & Yes & Yes \\
\hline Beasley $1996 a^{87}$ & 1996 & 50 & Placebo & Yes & Yes & No \\
\hline Beasley $1996 a^{87}$ & 1996 & 50 & Olanzapine & Yes & Yes & No \\
\hline Beasley $1996 b^{89}$ & 1996 & 69 & Haloperidol & Yes & Yes & Yes \\
\hline Beasley $1996 b^{89}$ & 1996 & 68 & Placebo & Yes & Yes & Yes \\
\hline Beasley $1996 c^{89}$ & 1996 & 133 & Olanzapine & Yes & Yes & Yes \\
\hline Borison $1996^{62}$ & 1996 & 55 & Placebo & Yes & Yes & Yes \\
\hline Borison $1996^{62}$ & 1996 & 54 & Quetiapine & Yes & Yes & Yes \\
\hline van Kammen $1996^{51}$ & 1996 & 105 & Sertindole & Yes & Yes & Yes \\
\hline van Kammen $1996^{51}$ & 1996 & 48 & Placebo & Yes & Yes & Yes \\
\hline Zborowski $1995 a^{55}$ & 1995 & 116 & Placebo & Yes & Yes & Yes \\
\hline Zborowski $1995 a^{55}$ & 1995 & 115 & Haloperidol & Yes & Yes & Yes \\
\hline Zborowski $1995 b^{55}$ & 1995 & 117 & Sertindole & Yes & Yes & Yes \\
\hline Clark $1972 \mathrm{a}^{43}$ & 1972 & 19 & Chlorpromazine & Yes & No & No \\
\hline Clark $1972 \mathrm{a}^{43}$ & 1972 & 18 & Placebo & Yes & No & No \\
\hline Clark $1972 b^{43}$ & 1972 & 18 & Loxapine & Yes & No & No \\
\hline Clark $1970 a^{61}$ & 1970 & 15 & Chlorpromazine & Yes & No & No \\
\hline Clark $1970 \mathrm{a}^{61}$ & 1970 & 14 & Placebo & Yes & No & No \\
\hline
\end{tabular}

